regret of all his friends this hope has not been realised, and we have to deplore his demise at a comparatively early age.

"In the profession generally, and also in the medico-psychological branch of it Dr. Morrison was regarded as a sound authority in his speciality and a successful superintendent and administrator. He was for many years a prominent member of the Medico-Psychological Association and the British Medical Association, and for a considerable period he acted, with much acceptance, as Secretary to the Herefordshire and Worcestershire Branch of the latter body, and quite lately as its President.

"In 19 II he was Vice-President and Secretary of the Neurological Section at the annual meeting of the British Medical Association, and he also gave valuable service to the old-established Herefordshire Medical Society. In these capacities he proved himself to be a man of many parts and generous sympathies.

"During his occupancy of the office of Superintendent at Burghill he saw great additions and improvements, with every one of which he was associated and for which he had unflinchingly laboured, thinking always of the comfort and wellbeing of the unfortunate people under his charge. For the welfare of the institu. tion he gave of his very best, and so high was his sense of duty, that even trivial details were not deemed too unimportant to engage his personal attention. The result of such devotion to duty, and the extra strain in several directions which he lately encountered no doubt contributed largely to his breakdown in health. In the committee room and at Association meetings Dr. Morrison was a forceful and convincing speaker. He upheld his views strongly when once convinced that they were sound, and was not slow to unmask anything which savoured of opportunism. Whatever he undertook he did it with all his might, without a thought of self or reward. Dr. Morrison did not make a great many really intimate friends; but to the few who had the privilege of his intimacy he gave the firm hand of friendship which lasted for all time. His was a large-hearted and generous nature which radiated sympathy and kindness to all those who came within its reach. Upright, unselfish to a fault, with a high sense of duty and universally beloved, he possessed a personality which will live in the memory of all who knew him."

Dr. W. H. Macfarlane.

On August 2nd, 1915, from heart failure, Dr. W. H. Macfarlane, Medical Superintendent of the Hospital for the Insane, New Norfolk, Tasmania. (Communicated by Dr. G. F. Read.)

\title{
CORRESPONDENCE.
}

To the Editors of The Journal of Mental Scirnce.

Sirs,-Dr. Mercier; in your January issue, defines "cause" as " the necessary connection between an action and the sequent change, or accompanying unchange, in the thing acted on." He had previously suggested that any circumstance which prevents a change should be called the "reason" rather than the cause of the "unchange." This is a good distinction, though it seems to put out of action the alternative clause in his definition. I do not, however, write to find fault, but to show how it is possible to come still nearer to the basis of the idea of causation by recognising yet another distinction-namely, that between cause and occasion. For example, in the case of Newton's traditional apple, the cause of the fall was gravity, the occasion was doubtless the giving way of the stalk. The following considerations will explain the distinction and show its importance.

Change is not supposed to take place per saltum; it is always regarded as a continuous process. A process of change in any system may be called complete when it begins from one state of static equilibrium and ends in another such state. Every process takes place by virtue of an expenditure of energy, and (when the whole of the system involved in a complete process is taken into account) the potential energy of the final state is always less than that of the initial state. Any process may be considered under two aspects, either ( 1 ) as a change from the equilibrium of greater potential energy, or (2) as a change to the equilibrium of less potential energy. Under the former aspect it is called the cause; under the latter aspect it is called the effect. 
The relation between cause and effect being that of different ways of looking at the same process, we have next to trace the relation between "occasion" and "consequence."

A balanced system may have its equilibrium either stable, or unstable ; in neither case can it begin to change without external interference, yet there is a marked difference between the two. If the equilibrium be stable the system has no potential energy, and any process of change which it undergoes must be the equivalent of (i.e., be caused by) the process of change in another system which may, for purposes of calculation, be merged with it into a single composite system.

On the other hand, when a system is in unstable equilibrium, it does possess potential energy, and if the balance be upset by the action of another system this potential energy may be liberated, and a process of change may be initiated which has no equivalent in the disturbing system. The changes in the two systems are then related, not as cause and effect, but as "occasion" and "consequence." For example, in a motor engine the movement of the machinery is the equivalent of, and caused by, the motion of expanding gas in the cylinders, and the expansion, again, is caused by the combination of the petrol with the oxygen of the air, which supplies all the energy; but this combination is occasioned by the ignition, which has little energy of its own, yet liberates a large quantity of potential energy from the unstable mixture of air and petrol.

George Shann.

\section{To the Editor of The Journal of Mental Science.}

Dear Sir,-You will remember that in a weak moment I consented to review some psychoanalytic literature for the Journal. In response to your request for a paper for the Journal I find that the style of psychoanalytic writers has so infected my mind that $\cdot \mathrm{I}$ am unable to write anything but the following, which I am afraid you will regard as a descent from the sublime to the ridiculous (sublimation). Your unhappy contributor,

$\mathbf{X}$.

\section{The Psychoses.}

It is entirely owing to the wonderful discoveries of the great master mind of the day (Freud) that we owe the fact that the psychoses are now understood. For did he not show us the way that when discussing paranoia a case of dementia pracox should prove useful as an example? When an idea rises into consciousness it is apt to be repressed into the preconscious, and finally submerged in the unconscious, with at least one censor and sometimes two ready to pounce upon it should it raise its unhappy head.

Our critics who fail to understand our position weakly ask for some proof of such a statement. Thereby they show their ignorance and unwittingly reveal that they themselves are suffering from unconscious complexes. If they refuse to look down the telescope of Galileo psychoanalysis cannot be held accountable. Besides this there are numerous cases in the literature which can be made to prove anything you like if only apperceived from the proper view-point. As a paradigm the following case may be quoted :-

A boy of six years of age, physically healthy, suddenly developed an acute psychosis lasting a few hours, with great depression, emotivity, and stereotyped movements. The family history revealed little of importance, except that a maternal grandfather had developed arcus senilis at the age of 70 . The anamnesis was that one afternoon he earnestly desired some chocolates, the property of his little sister. Undeterred by parental warning a conflict ensued. He seized the chocolates (wish-fulfilment) and greedily ate them, while his little sister cried bitterly. He did more, for he repressed the dearly-beloved doll of the sister into the water-butt at the corner of the house. On the return of his father from the city the boy denied having stolen the chocolates, and even if he had taken one or two, said he, it was because they were bad for the sister (rationalisation). Punishment was decided upon and duly administered by the father, during which the symptoms of agitation, stereotyped movements, etc., made their appearance. In addition a strong hatred-of-father complex appeared (Edipus complex), which lasted about the same length of time as the symptoms just detailed. The psychosis lasted but 